\title{
Peripheral facial palsy revealing neuroborreliosis
}

\begin{abstract}
Introduction: Neuroborreliosis (NB) is a bacterial infection with Borrelia burgdorferi $(\mathrm{Bb})$, targeting the peripheral and/or central nervous system. It appears on the secondary and tertiary phase of its evolution.

Observation: T.M is a 40 years-old man, previously healthy. He presented 7 days before his admission, a facial asymmetry, with swallowing disorders. These signs were evolving rapidly during a stay in a village. There was no history of migrant erythema, tick's spot, or fever. The clinical examination found a right peripheral facial palsy (PFP), hypoesthesia on the territory of the right Vth cranial nerve and hypokinesia of the right soft palate with dulled gag reflex. The clinical syndrome was unilateral cranial polyneuritis. The cerebral MRI showed a Gado enhancement of the right facial nerve above his emergence from the protuberance. The cerebro-spinal fluid (CSF) study found lymphocytic meningitis (14 Lymphocytes $/ \mathrm{mm} 3$ ) with elevated CSF protein $(0,6 \mathrm{~g} / 1)$. Exhaustive para clinical tests were performed and went negative. The Borreliosis serology was positive to $\operatorname{IgM}$ and negative to $\mathrm{IgG}$, with specific antiborrelia immunoglobulin intrathecal synthesis. The patient was treated by Ceftriaxone $2 \mathrm{~g} / 24 \mathrm{~h}$ during 14 days. The evolution was favorable, with partial regression of the PFP, and the control of the intrathecal immunoglobulin synthesis was negative.
\end{abstract}

Discussion: Lyme borreliosis is the most frequent ixodid tick-borne human disease in the world, with an estimated 85,500 patients annually. It is a multi-systemic disease caused by Borrelia burgdorferi sensu lato. A complete presentation of the disease is an extremely unusual observation, in which a skin lesion follows a tick bite, the lesion itself is followed by heart and nervous system involvement, and later on by arthritis; late involvement of the eye, nervous system, joints and skin may also occur. We reported an early Lyme neuroborreliosis case with atypical unilateral painless cranial meningo-polyneuritis. The diagnosis was confirmed biologically with favorable clinical and biological evolution after antibiotic treatment.

Conclusion: The absence of Tick, classical migrant erythema or painful meningopolyneuritis did not exclude neuroborreliosis diagnosis. In presence of LNB suggestive neurological syndrome, the detection of specific antibody in blood and CSF stay the mainstay for diagnosis of the disease.

Keywords: neuroborreliosis, facial palsy, meningopolyneuritis, anti-borrelia intrathecal synthesis
Volume 3 Issue 4 - 2018

\author{
Benmoh Y,' Ajamat M,' A Ahizoune,' Mnaili \\ MA,' Reggabi A,' Abida N,' Mounach J,' Satte \\ $A^{3}{ }^{3}$ Bourazza $A^{\prime}$ \\ 'Department of Neurology, MohamedV University, Morocco \\ ${ }^{2}$ Department of Neurophysiology, MohamedV University, \\ Morocco \\ ${ }^{3}$ Department of Neurophysiology, Sidi Mohamed Ben Abdellah \\ University, Morocco
}

Correspondence: Youssouf Benmoh, Faculty of Medicine and Pharmacy Rabat, MohamedV University, Rabat, Morocco, Tel +212675619652, Email youssouf1680@gmail.com

Received: April 04, 2018 | Published: July 09, 2018

\section{Introduction}

Neuroborreliosis (NB) is a bacterial infection with Borrelia burgdorferi $(\mathrm{Bb})$, targeting the peripheral and/or central nervous system. It appears on the secondary and tertiary phase of its evolution. The prevalence of Lyme neuroborreliosis is estimated to 85.500 patients annually, with variety from 10 in North Africa to 65.000 patients in Europe. ${ }^{1}$ Epidemiological results are different in European studies versus American ones: in a southern Sweden study, in 1.471 patients with Lyme diagnosis, EM was the most frequent symptom within $77 \%$, followed by neuroborreliosis (16\%), than arthritis $(7 \%){ }^{2}$ Man is accidently infected, while attending a moist biotope: underbrush, prairies or even city's garden. The spirochete spreads over a tick-bite, and causes local erythema migrans. The spontaneous evolution of the spirochete is involving the nervous system in a second phase.

\section{Observation}

T.M is a 40 years-old man, previously healthy. He presented 7 days before his admission, a facial asymmetry, with swallowing disorders. These signs were evolving rapidly during a stay in a village. There was no history of migrant erythema, tick's spot, or fever. The clinical examination found a right peripheral facial palsy (PFP) (Figure 1) hypoesthesia in the territory of the right $\mathrm{V}^{\text {th }}$ cranial nerve and hypokinesia of the right soft palate with dulled gag reflex. The clinical syndrome was unilateral cranial polyneuritis.

The cerebral MRI showed a Gadolinium enhancement of the right facial nerve above his emergence from the protuberance (Figure 2).

The cerebro-spinal fluid (CSF) study found lymphocytic meningitis (14 Lymphocytes/mm3) with elevated CSF protein $(0,6 \mathrm{~g} / \mathrm{l})$.

The complete count blood objectified leukocytosis: $16.10^{3}$ white cells $/ \mathrm{mm}^{3}$ made of neutrophil $\left(14.10^{3} / \mathrm{mm} 3\right)$.

Exhaustive para clinical tests were performed and went negative. It includes serology (Hepatitis B and C, HIV, syphilis, brucellosis, tuberculosis, HSV, CMV, EBV), immunological tests (antibody anti DNA, anti nuclear, anti SSA/SSB), angiotensin converting enzyme, phospho-calcic level in blood and urine and salivary gland biopsy. Plasmatic protein electrophoresis found low beta-1-globulinemia associated to discrete inflammatory syndrome.

The Borreliosis serology was positive to IgM and negative to $\mathrm{IgG}$, with specific anti-borrelia immunoglobulin intrathecal synthesis. 


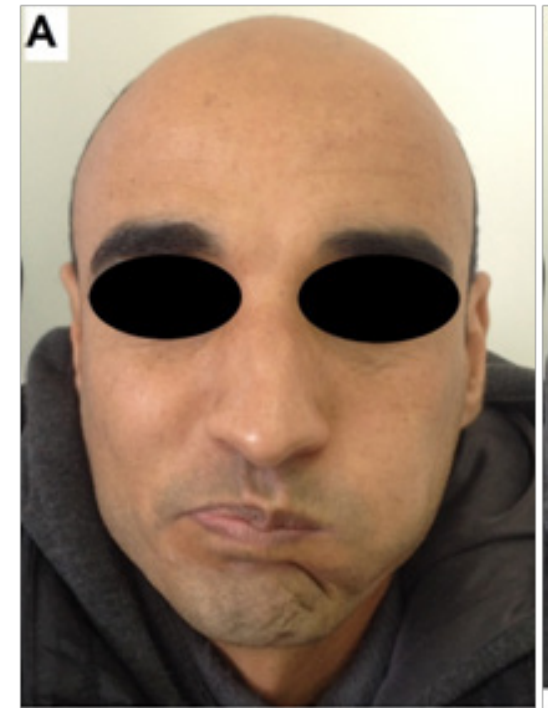

A.Asymmetric swelling cheeks.

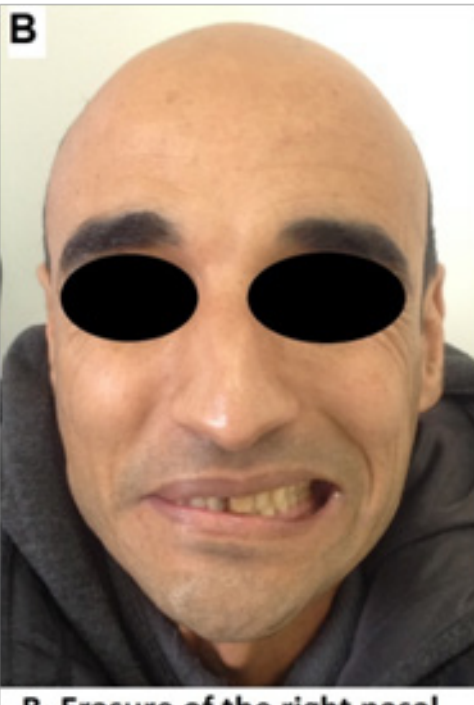

.B. Erasure of the right nasal labial line while forcing a smile.

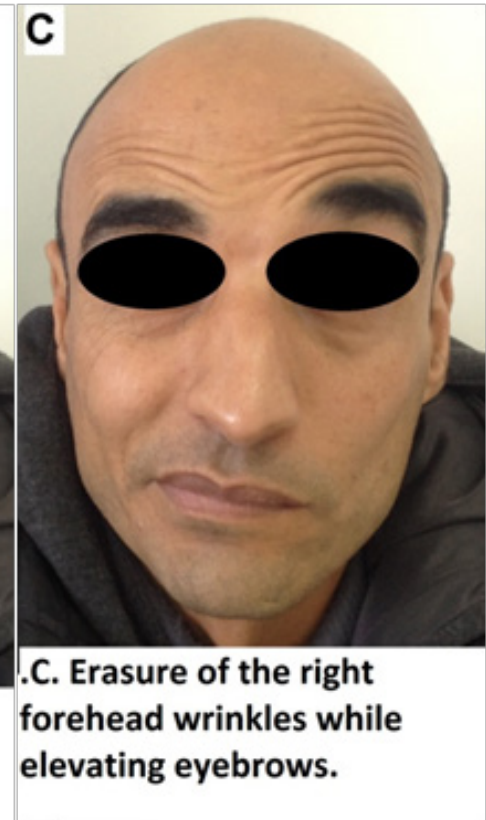

Figure I Pictures showing right facial palsy in different movements.

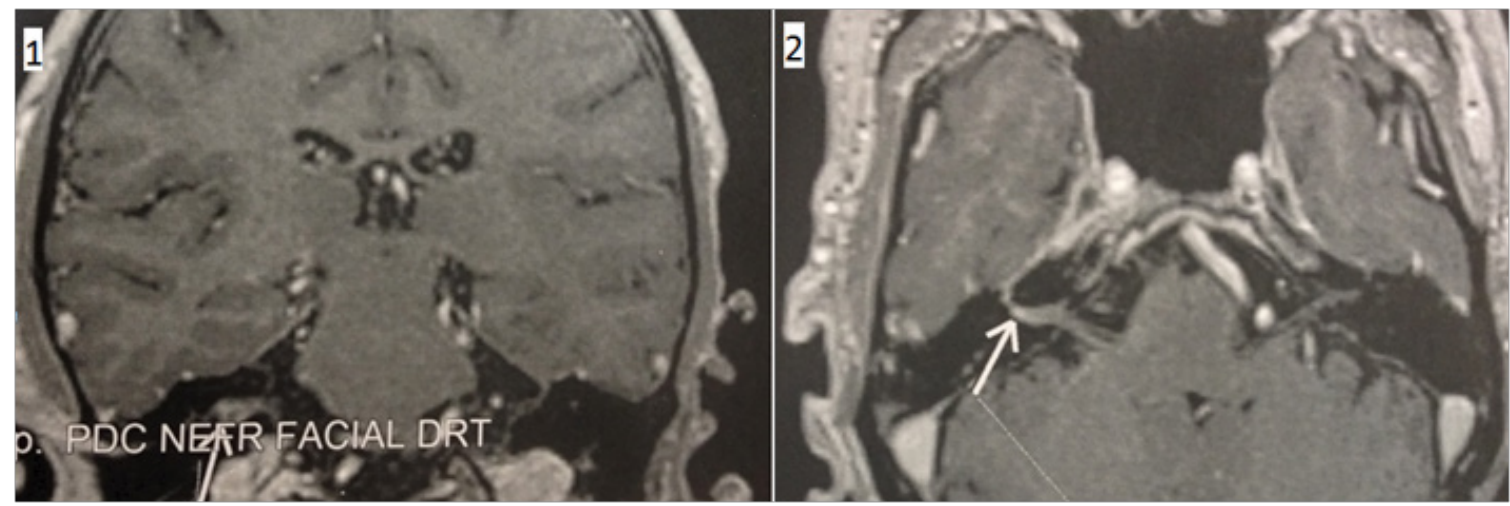

Figure 2 Cerebral MRI showing TI Gadolinium enhancing of the right facial nerve ( white arrow) on Coronal (I) and axial (2) sequences.

The patient was treated by Ceftriaxone $2 \mathrm{~g} /$ day during 14 days. The evolution was favorable, with partial regression of the PFP, and the control of the intrathecal immunoglobulin synthesis was negative.

\section{Discussion}

The Lyme disease name went to the first description of an epidemic arthritis among young children in Lyme district (Connecticus, east American coast) in the late 1970s. This happens after a long European history with its cutaneous manifestation at the end of the $19^{\text {th }}$ century. In 1982, Dr Willy Bourgdorfer discovered a spiral spirochete in the Ixodes scapularis (I. dammini) bowel. So the bacteria were named: Borrelia burgdorferi. ${ }^{3,4}$

The Ixodes ricinus thick need high humidity to survive, which explain its prevalence in the North hemisphere, where exist rainforest with dense underbrush. This exophilic vector contains a well adapted mouthpart to anchor and drill the skin like a harpoon. It needs blood meal at every stage of maturation (larva, nymph, adult) to achieve its cycle.

After a first blood meal on voles, the infected vector will accidently bite Man. If it remains attached less than 24 hours on the host, the transmission is rare, while after 72 hours the transmission is fully assured. This explains why it is strongly recommended to remove the tick as quickly as possible and to disinfect the bite site. In most cases, our immune system gets rid of the borrelies. In $4-5 \%$ of cases, a seroconversion may appear in the following months, and only $0,8 \%$ of the cases develop a migrant erythema. ${ }^{5}$

Borrelia burgdorferi is present in temperate region where Ixodes ricinus live. In Europe, six species of borrelia was described: Borrelia burgdorferi, B. garinii, B. afzelii, B. valaisiana, B. lusitaniae and B. bissettii, where only the 3 first species was found in patient's culture. ${ }^{6-9}$ Neuroborreliosis manifestations are fully caused by B.bugdorferi s.s in America. While in Europe, B.garinii is the most frequent, followed by B.afzeli and rarely by B.burgdorferi s.s. These results were based on serological and CSF studies with identifying different Borrelia genospecies. ${ }^{10}$

In chronic infection, the patient serological reaction ( $\operatorname{IgG})$ is directed against multiple proteins of Borrelia, and become more specific to species and more likely to strain of Borrelia. Thus, basing on the serological reaction and genetic typisation of Borrelia's stain, a correlation with symptomatic aspect was made: B.burgdorferi was 
found in Lyme arthritis, B.afzelii in chronic acrodermatis atrophicans and B.garinii in neuroborreliosis. ${ }^{11,12}$ These associations are not absolutes, as many Borrelias were isolated in cerebrospinal fluid study: $58 \%$ of B.garnii, $28 \%$ of B.afzelii and $11 \%$ of B.Burgdorferi. ${ }^{13,14}$

In European patients, meningo-polyneuritis is the most frequent manifestation of neuroborreliosis. The median period between the bite and the first neurological sign is 3 weeks (range 1-18 weeks), and two thirds of patient remember the arthropod bites. ${ }^{15,16} \mathrm{~A}$ well correlation was established between the EM localization and the initial radicular lesion. ${ }^{15}$ Histological studies in meningo-radiculoneuritis showed lymphocytic involvement of ganglia, leptomeninges, afferent and efferent rootlets with focal microgliosis. ${ }^{17-19}$ Our case had a delay of one week between his arrival to the village and the first symptom, with no history of migrant erythema.

Concerning clinical characteristics of early stage in adult, neuroborreliosis comprises meningopolyneuritis (MPN) with cranial and/or spinal nerve involvement called Garin-Bujadoux-Bannwarth's syndrome. Pain is the most striking sign resulting of radiculalgia; the pain is usually severe, lancinate and worsening by night, until depriving of sleep. ${ }^{20,21}$ Cranial neuropathy remains the most frequent sign in early neuroborreliosis, ${ }^{16}$ where uni/bilateral peripheral facial palsy is the most common symptom. ${ }^{22,23}$ In endemic area, one of 4 patients presenting VII nerve palsy in no winters month, are having Lyme borreliosis. ${ }^{24}$ Less frequently, neuroborreliosis cause III, VI and VIII nerve palsy. The CSF study in these forms currently shows lymphocytic pleocytosis, even those without any sign of meningitis, like our case. ${ }^{25-27}$ The other particularities of our case are the presence of atypical unilateral cranial polyneuritis (VII, V and mixed nerve) without typical radiculalgia or anterior migrant eyrthema; and the

Table 2 Lyme's disease Diagnosis criteria in Europe (EUCALB criteria). ${ }^{44,43}$
Gado enhancement of the VII ${ }^{\text {th }}$ cranial nerve on the MRI. If not treated in the acute form, spirochete leads to chronic manifestation observed months to years after the infection. The most frequent syndrome in this form is the chronic progressive encephalomyelitis and cerebral vasculitis. A peripheral nerve disorder may be seen in the chronic phase: axonal polyneuropathy associated with acrodermatitis chronic atrophicans $^{28-30}$ (Table 1).

Table I Frequency of neuroborreliosis forms in Europe. ${ }^{44}$

\begin{tabular}{ll}
\hline Neuroborreliosis form & Frequency \\
\hline Acute meningo-radiculitis & 67 to $85 \%$ \\
Acute meningitis & 4 to $5 \%$ \\
Acute myelitis & 4 to $5 \%$ \\
Acute encephalitis & 0,5 to $8 \%$ \\
stroke & $1 \%$ \\
Optic neuritis & $<0,5 \%$ \\
Polyneuropathy or other Peripheral neuropathy & $5 \%$ \\
Chronic encephalopathy & 4 to $6 \%$ \\
Encephalopathy & unknown \\
\hline
\end{tabular}

While the clinical syndrome made suspect a NB disease, physician needs biological confirmation. The detection of a specific antibody response in both blood and CSF remains the mainstay in the laboratory's diagnosis. The two practical tests available with best sensitivity and specificity are ELISA and immunoblot. The detection of intrathecal anti-borrelia immunoglobulin synthesis specify is near $95 \%$, with $75 \%$ sensibility, which stay superior to culture and PCR's ones. ${ }^{9}$ It must be notified that after a Bb contact, most of patients, even cured, stay positive to laboratory's tests. This concludes to the nonsignificance of a positive test without classical clinical form (Table 2) (Table 3).

\begin{tabular}{|c|c|c|c|c|}
\hline Clinical form & Necessary criteria & Optional criteria & Biological necessary criteria & Biological optional criteria \\
\hline $\begin{array}{l}\text { Acute } \\
\text { Neuroborreliosis }\end{array}$ & $\begin{array}{l}\text {-Painful meningo-radiculitis with } \\
\text { or without facial palsy or other } \\
\text { cranial nerve paralysis. } \\
\text {-In children: meningitis or } \\
\text { isolated facial nerve palsy (maybe } \\
\text { bilateral) or other cranial nerve } \\
\text { paralysis. }\end{array}$ & $\begin{array}{l}\text {-Simultaneous migrant } \\
\text { erythema or antecedent } \\
\text { of migrant erythema. }\end{array}$ & $\begin{array}{l}\text {-Intrathecal specific antibody } \\
\text { synthesis (could miss in early } \\
\text { stage) }\end{array}$ & $\begin{array}{l}\text {-Lymphocytosis in CSF } \\
\text { (could be missed in isolated } \\
\text { facial nerve paralysis or other } \\
\text { early form). } \\
\text {-Presence of specific IgG or } \\
\text { specific oligo-clonal bands } \\
\text { in CSF. } \\
\text {-Elevation of plasmatic level } \\
\text { of specific IgG or presence of } \\
\text { specific IgM. } \\
\text {-PCR or Culture positive to } \\
\text { B.burgdorferi. }\end{array}$ \\
\hline $\begin{array}{l}\text { Chronic } \\
\text { Neuroborreliosis }\end{array}$ & $\begin{array}{l}\text {-Persistant encephalitis, } \\
\text {-Encephalomyelitis } \\
\text {-Menigo-encephalitis, } \\
\text {-Radiculo-myelitis. }\end{array}$ & & $\begin{array}{l}\text {-Lymphocytosis in CSF with } \\
\text { intrathecal specific anti-body } \\
\text { synthesis and presence of } \\
\text { specific IgG in plasma. }\end{array}$ & \\
\hline
\end{tabular}

Table 3 The $16^{n}$ consensus conference of anti-Borrelia therapy: treatment of Neuroborreliosis. ${ }^{44}$

\begin{tabular}{|c|c|c|}
\hline Clinical situation & First line therapy & Second line therapy \\
\hline Isolated facial nerve palsy & $\begin{array}{l}\text {-Doxycycline PO } 200 \mathrm{mg} / \mathrm{d} 14 \text { to } 21 \text { days } \\
\text {-Or Amoxicillin PO } 1 \mathrm{~g} * 3 / \mathrm{d} 14 \text { to } 21 \text { days } \\
\text {-Or ceftriaxone IV } 2 \mathrm{~g} / \mathrm{d} 14 \text { to } 21 \text { days }\end{array}$ & \\
\hline $\begin{array}{l}\text { Others forms of Neuroborreliosis including facial nerve } \\
\text { palsy with meningitis }\end{array}$ & -Ceftriaxone IV $2 \mathrm{~g} / \mathrm{d} 21$ to 28 days & $\begin{array}{l}\text {-Penicillin G IV } 18-24 \mathrm{MU} / \mathrm{d} 21 \text { to } 28 \text { days } \\
\text {-Or Doxycycline PO } 200 \mathrm{mg} / \mathrm{d} 21 \text { to } 28 \text { days }\end{array}$ \\
\hline
\end{tabular}


In the early localized borreliosis, two objectives should be fixed: the first is to make EM disappear (which may happen spontaneously), the second one is to avoid the dissemination of the disease and the involvement of other organ systems. At this stage, three antibiotics are equally effective: Amoxicillin (oral), ceftriaxone (parenteral) and cefuroxime axetil (expensive). The duration varies from 10, 14 to 21 days, with no clearly superior effectiveness. ${ }^{31-34}$

For the early disseminated and late Lyme disease, antibiotics are less efficient. This is du not only to direct action of Borrelia, but also to immunological modification: a molecular mimicry was established between the bacteria antigens and neurological or articular antigens. $^{35,36}$ Also, the difficulty of diagnosing neuroborreliosis affects the evaluation of its treatment. Intravenous penicillin with high dosage had shown its effectiveness for neuroborreliosis. ${ }^{37}$ Equal or even better effectiveness was demonstrated for daily two grams intravenous ceftriaxone. No significant difference was established for higher ceftriaxone dosage. ${ }^{38,39}$ Following the EFNS recommendation, the use of oral doxycyclin (200 mg daily) showed equal effectiveness as intravenous ceftriaxone in the treatment of neuroborreliosis without involvement of central nervous system. If the central nervous system is involved (encephalitis, myelitis or vasculitis), the EFNS recommended intravenous ceftriaxone ( $2 \mathrm{~g}$ daily) for 14 days. ${ }^{40} \mathrm{In}$ adult, the prognosis of facial palsy secondary to Lyme disease seems to be good, as reported in USA series: $90 \%$ of patients improve to normal state. $^{22,24,41}$ Nevertheless, clinical and neurophysiologic examination in Swedish children with facial palsy showed mild sequelae. ${ }^{42}$

\section{Conclusion}

The absence of Tick, classical migrant erythema or painful meningo-polyneuritis did not exclude neuroborreliosis diagnosis. In presence of LNB suggestive neurological syndrome, the detection of specific antibody in blood and CSF stay the mainstay for diagnosis of the disease. In early disseminated and late borreliosis, suspected cases should be treated by antibiotic, because even if the diagnosis is not confirmed, it cannot be excluded. Primary prevention is crucial, by informing people, exposed one, and medical personnel about the disease, wearing long clothes in endemic zones and using repellent products.

\section{Acknowledgements}

None.

\section{Conflict of interest}

Author declares that there is no conflict of interest.

\section{References}

1. Lipsker, Dan, Jaulhac. Lyme disease Series: Current problems in dermatology. 2009

2. Berglund J, Eitrem R, Ornstein K, et al. An epidemiologic study of Lyme disease in southern Sweden. N Engl J Med. 1995;333: 13191327.

3. Steere AC, Broderick TF, Malawista SE. Erythema chronicum migrans and Lyme arthritis: Epidemiologic evidence for a tick vector. $A m J$ Epidemiol. 1978;108(4):312-321.

4. Burgdorfer W, Barbour AG, Hayes SF, et al. Lyme disease-a tick-borne spirochetosis?. Science. 1982;216(4552):1317-1319.
5. O Péter, G Praz. Lyme Borreliosis. Rev Med Suisse. 2002.

6. Baranton G, et al. Delineation of Borrelia burgdorferi sensu stricto, Borrelia garinii sp. nov., and group VS461 associated with Lyme borreliosis. Int J Syst Bacteriol. 1992;42:378-383.

7. Canica MM, Nato F, Merle L, et al. Monoclonal antibodies for identification of Borrelia afzelii sp. nov. associated with late cutaneous manifestations of Lyme borreliosis. Scand J Infect Dis. 1993;25:441448.

8. Le Fleche A, et al. Characterization of Borrelia lusitaniae sp. nov. by $16 \mathrm{~S}$ ribosomal DNA sequence analysis. Int $J$ Syst Bacteriol. 1997;47:921-925.

9. Wang G, van Dam AP, Le Fleche A, et al. Genetic and phenotypic analysis of Borrelia valaisiana sp. nov. (Borrelia genomic groups VS116 and M19). Int J Syst Bacteriol. 1997;47(4):926-932.

10. Strle F, Ružić SE, Cimperman J, et al. Comparison of findings for patients with Borrelia garinii and Borrelia afzelii isolated from cerebrospinal fluid. Clin Infect Dis. 2006;43(6):704-710.

11. Anthonissen FM, De Kesel M, Hoet PP, et al. Evidence for the involvement of different genospecies of Borrelia in the clinical outcome of Lyme disease in Belgium. Res Microbiol. 1994;145(4):327-331.

12. Assous MV, Postic D, Paul G, et al. Western blot analysis of sera from Lyme borreliosis patients according to the genomic species of the Borrelia strains used as antigens. Eur J Clin Microbiol Infect Dis. 1993;12(4):261-268.

13. Péter O, Bretz AG, Postic D, et al. Association of distinct species of Borrelia burgdorferi sensu lato with neuroborreliosis in Switzerland. Clinical Microbiology and Infection. 1997;3(4):423-431.

14. Ryffel K, Péter O, Rutti B, et al. Scored antibody reactivity determined by immunoblotting shows an association between clinical manifestations and presence of Borrelia burgdorferi sensu stricto, B. garinii, B. afzelii, and B. Valaisiana in humans. J Clin Microbiol. 1999; 37(12):4086-4092.

15. Pfister HW, Kristoferitsch W, Meier C. Early neurological involvement (Bannwarth's syndrome); in: Weber K, Burgdorfer W editors. Aspects of Lyme Borreliosis. 1993;152-167.

16. Kristoferitsch W. Neuropathies in lyme disease. Wien, Springer; 1989.

17. De Koning J, Duray PH: Histopathology of human Lyme borreliosis; in Weber K, Burgdorfer W. editors. Aspects of Lyme Borreliosis. 1993;7092.

18. Duray PH. Clinical pathologic correlations of Lyme disease. Rev Infect Dis. 1989;11(Suppl 6):S1487-S1493.

19. Meurers B, Kohlhepp W, Gold R, et al. Histopathological findings in the central and peripheral nervous systems in neuroborreliosis: a report of three cases. J Neurol. 1990;237(2):113-116.

20. Pachner AR, Steere AC. The triad of neurologic manifestations of Lyme disease: meningitis, cranial neuritis, and radiculoneuritis. Neurology. 1985;35(1):47-53.

21. Kristoferitsch W. Neurological manifestations of Lyme borreliosis: clinical definition and differential diagnosis. Scand J Infect Dis. 1991;77(Suppl):64-73.

22. Clark JR, Carlson RD, Sasaki CT, et al. Facial paralysis in Lyme disease. Laryngoscope. 1985;95(11):1341-1345.

23. Shapiro ED, Gerber MA. Lyme disease and facial nerve palsy. Arch Pediatr Adolesc Med. 1997;151(12):1183-1184. 
24. Halperin JJ, Golightly M. Lyme borreliosis in Bell's palsy. Long Island Neuroborreliosis Collaborative Study Group. Neurology. 1992;42(7):1268-1270.

25. INVS. Lyme disease, Data from surveillance network in Alsace. $2005 ; 1-44$.

26. Tranchant C, Warter JM. Lyme disease. Rev Neurol. 2003;159:23-30.

27. Blanc F. Neurologic and psychiatric manifestations of Lyme disease. Med Mal Infect. 2007;37:435-445.

28. Hansen K, Lebech AM. The clinical and epidemiological profile of Lyme neuroborreliosis in Denmark 1985-1990. A prospective study of 187 patients with Borrelia burgdorferi specific intrathecal antibody production. Brain. 1992;115(Pt 2):399-423.

29. Oschmann P, Dorndorf W, Hornig C. Stages and syndromes of neuroborreliosis. J Neurol. 1998;245:262-272.

30. Christmann D, Hansmann Y, Erhart A. Aspects cliniques des manifestations neurologiques au cours de la borréliose de Lyme. Med Mal Infect. 1998;28:354-358.

31. Weber K, Preac MV, Wilske B. A randomized trial of ceftriaxone versus oral penicillin for the treatment of early European Lyme borreliosis. Infection. 1990;18:91-396.

32. Nadelman RB, Luger SW, Frank E. Comparison of cefuroxime axetil and doxycycline in treatment of early Lyme disease. Ann Intern Med. $1992 ; 117: 273-280$

33. Wormser GP, Ramanathan R, Nawakowski J, et al. Duration of antibiotic therapy for early Lyme disease: a randomized, double blinded, controlled trial. Ann Intern Med. 2003;138:697-704.

34. Nawakowski J, Nadelman RB, Forseter G. Doxycycline versus tetracycline therapy for Lyme disease associated with erythema migrans. J Am Acad Dermatol. 1995;32:223-227.
35. Steere AC, Gross D, Meyer AL, et al. Auto-immune mechanism in antibiotic treatment-resistant Lyme arthritis. $J$ Autoimmun 2001;16(3):263-268.

36. Drouin EE, Glickstein LJ, Steere A. Molecular characterization of the OspA 161175 T cell epitope associated with treatment resistant Lyme arthritis: differences among the three pathogenic species of Borrelia burgdorferi sensu lato. J Autoimmun. 2004;23:281-292.

37. Steere AC, Pachner AR, Malawista SE. Neurologic abnormalities of Lyme disease: successful treatment with high-dose intravenous penicillin. Ann Intern Med. 1983;99:767-772.

38. Dattwyler RJ, Halperin JJ, Volkman DJ, et al. Treatment of late Lyme borreliosis - randomized comparison of ceftriaxone and penicillin. Lancet. 1988;1(8596):1191-1194.

39. Mulleger RR, Millner MM, Stanek G, et al. Penicillin G sodium and ceftriaxone in the treatment of neuroborreliosis in children a prospective study. Infection. 1991;19(4):279-283.

40. Mygland A1, Ljøstad U, Fingerle V, et al. EFNS guidelines on the diagnosis and management of European Lyme neuroborreliosis. European Journal of Neurology. 2010;17(1):8-16.

41. Halperin JJ. Nervous system Lyme disease. Infect Dis Clin North Am. 2008;29(2):241-253.

42. Bagger SD, Remahl S, Ericsson M. Longterm outcome of facial palsy in neuroborreliosis. Otol Neurotol. 2005;26(4):790-795.

43. European Union Concerted Action on Lyme Borreliosis: Diagnosis of Lyme borreliosis.

44. Tafani C, Meningoradiculitis AI. A classic but unknown form of neuroborreliosis. Pratique Neurologique-FMC. 2014;5:294-297. 